\title{
Ambulatory Detection of Volatile Organic Compounds (VOCs) Associated with Depression
}

\author{
Donatini Bruno*, and Le Blaye Isabelle \\ Medicine Information Formation SA (Research), Cormontreuil, France
}

*Corresponding author: Donatini Bruno, Medicine Information Formation SA (Research), Cormontreuil, France, Tel: 06-08-58-46-29; E-mail: donatini@orange.fr

Received: 08 Apr, 2020 | Accepted: 23 Apr, 2020 | Published: 28 Apr, 2020

Citation: Donatini B, Le Blaye I (2020) Ambulatory Detection of Volatile Organic Compounds (VOCs) Associated with Depression. J Clin Case Stu 5(2): dx.doi.org/10.16966/2471-4925.199

Copyright: Donatini B, et al. This is an open-access article distributed under the terms of the Creative Commons Attribution License, which permits unrestricted use, distribution, and reproduction in any medium, provided the original author and source are credited.

\section{Abstract}

Background: Depression has been associated with dysbiosis and transit disturbances.

Objective: We investigated whether a new ambulatory device (X-PID $8500^{\circ}$ ) may detect a specific gas associated with depression.

Methods: A retrospective analysis of data collected during routine consultations for Small Intestinal Bowel Overgrowth.

Results: 117 patients were included. 48 patients presented with a peak between 92 and 97 seconds (m-xylene peak). 69 patients did not exhale VOCs detectable within this range. 32 patients had a recent medical history of depression. 22 of them presented with m-xylene peak whereas the 10 remaining patients did not $(45.8 \%$ versus $14.5 \%$; $<0.001) .8$ patients presented with ulcerative colitis: 7 of them presented with m-xylene peak $(p<0.001) .8$ patients have a medical history of severe acne treated with isotretinoin. Only two of them exhaled $m-x y l e n e(p<0.001)$.

Constipation was more frequent in patients with depression (19.4\% versus $11.8 \%$; $p<0.01)$ and was not associated with m-xylene. Two different mechanisms are possible and are discussed. The probability to find $\mathrm{m}$-xylene peak in a non-depressive patient remains high. However, such a peak may precede a depressive decompensation. Further investigations and follow-up are required to clarify this issue.

Conclusion: X-PID $8500^{\circ}$ can detect VOCs associated with a subgroup of depression in clinical ambulatory practice.

Keywords: Breath test; Depression; Chromatography

\section{Introduction}

Depression has been associated with numerous gastroenterological pathologies: e.g. constipation [1-3], overweight [4-7], gastroparesis [8-11], Ulcerative Colitis (UC) or Crohn's Disease (CD) [12], Irritable Bowel Syndrome (IBS) $[13,14]$ or periodontitis [15].

Some Volatile Organic Compounds (VOCs) have been associated with central nervous system disturbances in animals [16-18] as well as in human exposed to toxics [19]. These VOCs could be produced by the microbiota [20].

However, to our knowledge, no publication has reported a link between exhaled-VOCs and depression (confirmed by the Hamilton Anxiety Depression Scale) in human. A new ambulatory device, X-PID 8500; see details in the "Material and Methods" section - may detect $50 \mathrm{ppb}$ of VOCs and can be used in clinical practice since it takes only 2 minutes to get reliable chromatographic curves of exhaled VOCs.

We investigated whether X-PID $8500^{\circ}$ may detect a specific gas associated with depression. Herpes viruses were taken into consideration since they are suspected to favour gastroparesis [21-24] or periodontitis [25-30]. Cytomegalovirus has also been implicated in the occurrence of depression $[31,32]$, obesity $[33,34]$, or UC [35].

\section{Material and Methods}

This is a descriptive retrospective epidemiological study. Data were collected during the normal course of routine gastroenterological consultations for Small Intestinal Bowel Overgrowth (SIBO), from January 15, 2020 until March 15, 2020. There was no hypothesis testing before data collection, no data collection beyond that which is part of routine clinical practice, no scheduled data analysis before the work has already been done. This retrospective analysis of Case Series cannot therefore be qualified as "research" and does not requires approval from ethics boards designed to protect humans involved in clinical research, according to the International Committee of Medical Journal Editors (ICMJE).

\section{Inclusion criteria}

Patients consulting for SIBO and who underwent a breath test. Patients should provide with a full medical history, especially 
regarding Herpes simplex, Herpes zoster, periodontitis, constipation, previous treatment of acne with isotretinoin, ulcerative colitis, depression, thyroid pathologies, body weight and height, diabetes mellitus. Diabetes mellitus, when present, should be stabilized. CMV serology and transabdominal plus thyroid ultrasound examinations are routinely performed in patients consulting for SIBO. Patients signed a written consent for the possible retrospective epidemiological use of collected data.

\section{Exclusion criteria}

Ongoing tobacco abuse; lack of CMV serology analysis; lack of transabdominal or thyroid ultrasound examination; lack of signed consent for retrospective epidemiological use of data; uncontrolled diabetes mellitus; lack of breath test or recent intake of antibiotic therapy or of essential oils leading to massive destruction of the digestive flora and less than $2 \mathrm{ppm}$ of VOCs at the first measure, after 10 hours of fasting; uncontrolled endocrine disease (including thyroid insufficiency); incomplete data on drug or food complement intake.

\section{Depression}

The diagnosis of depression was usually already made by the general practitioner of the patient. The depressive mood was confirmed by the Hamilton rating scale for Depression [36,37] according to the French regulatory guidance [38]. The questionnaire was submitted and completed at the time of gas analysis by the X-PID $8500^{\circ}$.

\section{Transabdominal ultrasound examination}

Ileal distension was diagnosed as soon as ileal diameter reached 2.2 $\mathrm{cm}$ at the ileocoecal junction [39]. Lack of gastro-duodenal voiding was diagnosed when no evacuation of bubbles between the superior mesenteric artery and the aorta was observed after 2 minutes of osteopathic abdominal manoeuvres [40]. Jejunal hypotonia could also be implicated. In that case, the jejunum contains few bubbles and no peristalsis is visualized [39].

\section{Gas measurement}

The patient comes after at least 10 hours of fasting. He/she inhales room air and hold his/her breath for 20 seconds. He/she exhales the air in a first neutral plastic bag (1.3 litres) and afterwards he/she exhales at least $100 \mathrm{ml}$ (expected to belong to the expiratory reserve volume) in a second neutral plastic bag (Contralco', Gignac, France; www.contralco. com). VOCs from the second bag are then immediately measured by the X-PID $8500^{\circ}$, an ambulatory gas chromatograph associated with Photoionization Detection technology [Dräger, Lubeck, Germany; www.draeger.com > Products > Multi-Gas-Detectors].

Isobutylene or methylacetate are detected within 5.6 to 6.4 seconds, isobutyric, butyric and acetic acids between 7.0 and 7.9 seconds, toluene between 39 and 45 seconds, m-xylene or p-xylene between 92 and 97 seconds and o-xylene around 115 seconds.

$\mathrm{X}$-PID $8500^{\circ}$ does not detect hydrogen and is therefore not suitable for the detection of SIBO related to sugar-malabsorption. X-PID $8500^{\circ}$ was used after breath holding and only after fasting, not after sugar intake.

The air of the first bag is analysed by the Dräger X-am 8000 . We routinely use the Dräger X-am 8000 [Dräger, Lubeck, Germany; www.draeger.com > Products > Multi-Gas-Detectors] to measure hydrogen before and two hours after the intake of lactulose in order to diagnose SIBO related to sugar-malabsorption. Results will be published separately. This device is also able to measure nitric oxide and hydrogen sulphide.
When SIBO is suspected, VOCs as well as hydrogen, nitric oxide and hydrogen sulphide are measured systematically and concomitantly, with these two methods and devices.

Both devices are easily portable and equipped with powerful pumps. Patients could be placed in separate rooms when necessary. The setup is basic and similar for both devices. It requires only a short tube to connect the bag and the device.

The results are exportable in excel tables.

\section{Statistics}

Comparisons of means were performed using independent student's t-test. Comparisons of percentage used two-sample t-tests. Yates correction was used for small samples. The Poisson distribution was used for the analysis of very rare events.

The VOCs peak which has been the most frequently observed in depressive patients was selected to perform the initial statistical analysis according to parameters with an established impact on depressive mood.

Since higher frequency of depression in female is established, a statistical analysis was performed to compare percentages between men and women. Since constipation is an established key factor associated with depression, a statistical analysis was performed to compare patients with and without constipation.

Sensitivity, false positive ratio, negative predictive value, positive predictive value and ROC curve were calculated for the most relevant VOCs peak.

\section{Results}

This descriptive retrospective epidemiological analysis included 117 patients. The descriptive demographic data are summarized in table 1.32 patients $(27.4 \%)$ had depression. 22 of them presented with a m-xylene peak $(68.8 \%)$ whereas only 26 non-depressive patients (out of the 85 remaining patients) exhaled detectable m-xylene peak (30.6\%; $\mathrm{p}<0.001)$.

A statistical analysis was therefore performed according to the m-xylene peak. All parameters with an established impact on depressive mood were taken into consideration. See table 2 for statistically significant parameters and results. Other parameters not presented in table 2 were not statistically significant regarding the difference between the two groups: altered gastric voiding $(70.8 \%$ versus $58.0 \%$ ), jejunal hypotonia ( $36.2 \%$ versus $21.7 \%$ ), constipation ( $12.8 \%$ versus $14.5 \%$ ), periodontitis ( $50.0 \%$ versus $53.6 \%$ ), overweight (39.6\% versus $49.3 \%)$, adenocarcinoma (10.6\% versus $13.0 \%)$ or nodular thyroiditis (19.1\% versus $26.1 \%$ ). Since higher frequency of

Table 1: Descriptive demographic data of the 117 included patients, according to the $\mathrm{m}$-xylene peak.

\begin{tabular}{|l|c|c|}
\hline & $\begin{array}{c}\text { Patients with } \\
\text { m-xylene peak } \\
\text { (48 patients) }\end{array}$ & $\begin{array}{c}\text { Patients without } \\
\text { m-xylene peak } \\
\text { (69 patients) }\end{array}$ \\
\hline Males (39 patients) & 14 & 25 \\
\hline Females (78 patients) & 34 & 44 \\
\hline Age & $47.6 \pm 18.9$ & $49.7 \pm 19.4$ \\
\hline Body weight & $63.3 \pm 17.1$ & $64.1 \pm 16.3$ \\
\hline Height & $167.9 \pm 9.5$ & $164.0 \pm 17.3$ \\
\hline Body Mass Index & $22.2 \pm 4.8$ & $25.3 \pm 17.8$ \\
\hline
\end{tabular}


Table 2: Comparison of statistically significant parameters between patients with or without $\mathrm{m}$-xylene peak.

\begin{tabular}{|l|c|c|c|}
\hline & $\begin{array}{c}\text { Patients with } \\
\text { m-xylene peak } \\
\text { (48 patients) }\end{array}$ & $\begin{array}{c}\text { Patients without } \\
\text { m-xylene peak } \\
\text { (69 patients) }\end{array}$ & P values \\
\hline Depression & $22(45.8 \%)$ & $10(14.5 \%)$ & $<0.001$ \\
\hline Ulcerative colitis & $7(14.6 \%)$ & $1(1.4 \%)$ & $<0.001$ \\
\hline Isotretinoin use & $2(4.2 \%)$ & $6(8.7 \%)$ & $<0.001$ \\
\hline IgG CMV+ & $2(4.2 \%)$ & $9(13 \%)$ & $<0.001$ \\
\hline Crohn's disease & 0 & 4 & $<0.001$ \\
\hline $\begin{array}{l}\text { Exhaled voCs } \\
\text { between 39 and }\end{array}$ & $29(60.4 \%)$ & $29(42.0 \%)$ & $<0.05$ \\
\hline 45 seconds & $16(33.3 \%)$ & $34(49.3 \%)$ & $<0.05$ \\
\hline Herpetic flares & & & \\
\hline
\end{tabular}

The percentages are equal to the number of cases per cell divided by the number of cases with $\mathrm{m}$-xylene peak or without $\mathrm{m}$-xylene peak.

Table 3: Comparison of key parameters between male and female.

\begin{tabular}{|l|c|c|c|}
\hline & $\begin{array}{c}\text { Male } \\
\text { (39 cases) }\end{array}$ & $\begin{array}{c}\text { Female } \\
\text { (78 cases) }\end{array}$ & P values \\
\hline Constipation & $1(2.6 \%)$ & $15(19.2 \%)$ & $<0.001$ \\
\hline Adenocarcinoma & $2(5.1 \%)$ & $12(15.4 \%)$ & $<0.001$ \\
\hline Depression & $7(17.9 \%)$ & $25(32.1 \%)$ & $<0.01$ \\
\hline Overweight & $17(43.6 \%)$ & $20(25.6 \%)$ & $<0.01$ \\
\hline Isotretinoin & $4(10.3 \%)$ & $5(6.4 \%)$ & $<0.01$ \\
\hline Ulcerative colitis & $2(5 \%)$ & $6(8 \%)$ & $<0.05$ \\
\hline Age (years of age \pm SD) & $45 \pm 19$ & $51 \pm 19$ & $>0.05$ \\
\hline m-xylene peak & $16(41.0 \%)$ & $31(39.7 \%)$ & $>0.05$ \\
\hline Herpetic flares & $16(41.0 \%)$ & $35(44.9 \%)$ & $>0.05$ \\
\hline IgG CMV+ & $3(8 \%)$ & $8(10.3 \%)$ & $>0.05$ \\
\hline Crohn's disease & $1(2.6 \%)$ & $3(4 \%)$ & $>0.05$ \\
\hline
\end{tabular}

The percentages are equal to the number of cases per cell divided by the number of males or females.

depression in female is established, a statistical analysis was performed to compare percentages between men and women (see table 3).

Since constipation is an established key factor associated with depression, a statistical analysis was performed to compare patients with and without constipation (see table 4). This analysis confirms that constipation and depression are statistically linked $(p<0.01)$. The $\mathrm{m}$-xylene peak does not characterize the group with constipation.

A higher percentage of adenocarcinoma in female should be emphasized $(15.4 \%$ versus $5.1 \%$; $\mathrm{p}<0.001)$. In addition, all reports of adenocarcinoma concerns patients without constipation $(0 \%$ versus $13.8 \% ; \mathrm{p}<0.001)$. Although not statistically significant, the difference of age between male and female ( $45 \pm 19$ versus $51 \pm 19)$ may explain the difference of percentages of cancer between these two populations, especially when earlier age of occurrence of cancer in female is taken into account ( 1 in 50 for men of less than 50 years of age versus 1 in 21 for women from 50 to 59 years of age [41]).

The sensitivity of $\mathrm{m}$-xylene peak regarding depression is equal to $80 \%$ and the false positive rate is equal to $27 \%$ (the specificity is
Table 4: Comparison of key parameters between patients with or without constipation.

\begin{tabular}{|l|c|c|c|}
\hline & $\begin{array}{c}\text { Constipation } \\
\text { (16 cases) }\end{array}$ & $\begin{array}{c}\text { No constipation } \\
\text { (101 cases) }\end{array}$ & P values \\
\hline Adenocarcinoma & $0(0 \%)$ & $14(13.8 \%)$ & $<0.001$ \\
\hline Ulcerative colitis & $0(0 \%)$ & $8(8.0 \%)$ & $<0.001$ \\
\hline Crohn's disease & $0(0 \%)$ & $4(4 \%)$ & $<0.001$ \\
\hline Depression & $5(43.8 \%)$ & $25(24.8 \%)$ & $<0.01$ \\
\hline Isotretinoin & $2(12.5 \%)$ & $7(6.9 \%)$ & $<0.01$ \\
\hline Age (years of age) & $50 \pm 17$ & $55 \pm 17$ & $>0.05$ \\
\hline Overweight & $8(50.0 \%)$ & $45(44.6 \%)$ & $>0.05$ \\
\hline m-xylene peak & $6(37.5 \%)$ & $41(40.6 \%)$ & $>0.05$ \\
\hline Herpetic flares & $8(50.0 \%)$ & $43(42.6 \%)$ & $>0.05$ \\
\hline IgG CMV+ & $2(12.5 \%)$ & $9(9 \%)$ & $>0.05$ \\
\hline
\end{tabular}

The percentages are equal to the number of cases per cell divided by the number of cases with constipation or without constipation.

therefore equal to $73 \%$ ). The negative predictive value of the $\mathrm{m}$-xylene peak is equal to $86.4 \%$ and the positive predictive value is equal to $81.3 \%$.

\section{Discussion}

The m-xylene peak may help to identify a new subgroup of patients at risk of depression, different from the one with constipation. This peak is independent of gender, of constipation of gastroparesis/ herpetic infections. Therefore, a new mechanism leading to depressive mood and associated to $\mathrm{m}$-xylene peak is possible.

We stated that the m-xylene peak could include the gas m-xylene which is known to induce central nervous system toxicity in human workers, especially in case of concomitant ethanol ingestion [19]. In animals, the m-xylene-induced central nervous system toxicity, especially when associated with toluene (peak between 39- and 45 seconds) is established [17-19]. UC is associated with high levels of exhaled VOCs [42-45] including pentanes and hexanes [46].

Isotretinoin has been reported to favour malabsorption, probably due to mTor inhibition and decrease in small-gut-epithelial stem cell population. Consequently, microbiota is altered, leading to modifications of exhaled VOCs such as increased methylacetate levels [47]. Isotretinoin could therefore skew the distribution of exhaled VOCs towards methylacetate (extracted within less than 8 seconds), decreasing the m-xylene peak.

Exhaled VOCs strongly correlate with alterations of the gut microbiome in CD [48] which is characterized by a low diversity of microbiome [49] and low level of VOCs [50-53].

In $\mathrm{CD}$, depression is mainly associated with flares [12]. It is noteworthy to specify that SIBO may spuriously mimic CD flares [54]. In such instances, depression may not be related to CD-related gas but to SIBO-related ones. It is then not surprising that ambulatory patients with stabilized CD did not exhale the m-xylene peak.

IgG CMV+ has been associated with depression [31,32]. In this descriptive study, IgG CMV+ was inversely associated with the $\mathrm{m}$-xylene peak $(\mathrm{p}<0.001)$. Although CMV infection is frequently reported in UC [36], its prevalence remains low (6/1000 patients) and cannot skew our results. Herpetic flares were not associated with the $\mathrm{m}$-xylene peak. We can therefore hypothesize that the $\mathrm{m}$-xylene peak cannot be attributed to herpes-induced gut dysmotility. 
The sensitivity of the $\mathrm{m}$-xylene peak regarding the diagnosis of depression is equal to $80 \%$ and specificity $73 \%$. The negative predictive value of the m-xylene peak is equal to $86.4 \%$ and the positive predictive value is equal to $81.3 \%$. Although the probability to find the $\mathrm{m}$-xylene peak in a non-depressive patient remains high, these figures suggest the use of this ambulatory, harmless and inexpensive method in usual clinical practice, especially in patients without constipation. In addition, the m-xylene peak may precede a depressive decompensation or may be a scar of previous depressive episode(s). Further investigations and follow-up are required to clarify this issue.

In order to oversimplify the physician's diagnostic (and perhaps etiopathogenic) tree we suggest classifying depression into two categories: category 1 with the $\mathrm{m}$-xylene peak, no constipation and a high risk of UC and category 2 with constipation, no m-xylene peak and low risk of UC.

\section{Constipation, methane production and secondary bile acids (hindgut involvement)}

Constipation is associated with methanogenesis and depression [13,55-57]. Fecal analysis in depressive patients display altered microbiota $[58,59]$. Studies in mice confirmed that faecal transplantation may induce depression in healthy animals [60]. Then one group of depression appears clearly associated with colonic dysbiosis.

Methanogenesis is not associated with overweight [61] and decreases the synthesis of long chain fatty acid like ceramides [62]. Methanogenesis is blocked by secondary bile acids which are deconjugated by altered small gut bacteria and therefore SIBO [63]. Constipation associated with methanogenesis is due to isolated cecal or colonic dysbiosis which does not deconjugate bile acids since bile acids are reabsorbed in the ileum and therefore do not reach the caecum. In constipated patients producing methane, breath test with lactulose fails to detect hydrogen [64]. Transabdominal ultrasound examination detects ceco-ileal reflux with the ileum inflated by gas, as well as decreased gastroduodenal voiding without jejunal movements and without jejunal inflammation [39]. Depression is associated with Irritable Bowel Syndrome (IBS) $[65,66]$.

IBS subjects with methane on lactulose breath test have lower postprandial serotonin levels than subjects with hydrogen [64]. In IBS patients, constipation is correlated with a decreased density of endocrine cells secreting serotonin [65-67]. Antibiofilm agents may activate colonic serotonin receptors [68]. This latter point may explain the link between constipation, dysbiosis and depression.

Colorectal immunity and constipation are linked. CD3+ and CD4+ cell counts in rectal and terminal ileal are lower in patients with IBS, especially in those with constipation [69]. Compared to male IBSpatients, female IBS-patients had greater numbers of mast cells and lower numbers of $\mathrm{CD} 3+$ and $\mathrm{CD} 8+\mathrm{T}$ cells in the colo-rectal mucosa [70].

\section{Altered gastroduodenal voiding (foregut involvement): A link with herpetic infections?}

Gastroparesis is associated with depression and decreased quality of life [8-11]. Gastroparesis is associated with obesity [71]. Gastroparesis may be a physiologic consequence of ileal distension [72] which induces GLP-1 synthesis which is implicated in satiety and blocks gastroduodenal voiding [73-76]. A diameter of the ileocecal junction higher than $2.2 \mathrm{~cm}$ after 10 hours fasting highly suggests chronic ileal distension associated with an altered GLP-1 synthesis and a metabolic syndrome [39].
Altered GLP-1 synthesis triggers CMV-induced inflammation of adipocytes with chronic low-grade inflammation due to an increased production of IL-6 leading to osteopenia, cardiovascular diseases and type 2 Diabetes mellitus [76,77]. This latter point may explain why IgG $\mathrm{CMV}+$ is inversely associated with the m-xylene peak.

Diabetes mellitus, herpetic infections, neurodegenerative diseases and some medications (such as anticholinergic agents) may induce gastroparesis [21]. Herpes simplex type 1 infects myenteric neurons [22], activates macrophages which produce reactive oxygen and peroxide-nitrogen species. These oxidative agents directly harm enteric neurons resulting in gastrointestinal dysmotility [23,24]. Our descriptive study did not find any convincing association between on one hand depression and on the other hand herpes infections, gastroparesis or overweight.

All collected information suggests that depressive patients could be classified within two groups: one with $\mathrm{m}$-xylene peak (not influenced by gender, constipation, gastroparesis/overweight or herpetic flares) and one with constipation (influenced by gender; however not influenced by gastroparesis/overweight or herpetic flare). The latter group could be associated with altered colonic secretion of serotonin.

\section{Conclusion}

The breath test performed by X-PID $8500^{\circ}$ was able to detect a peak associated with depression. It appears to mainly concern a sub-group of patients without constipation.

Although the positive predictive value of the m-xylene peak regarding depression is only equal to $81.3 \%$, this peak is reliable enough to plea for the use of this ambulatory new device in medical gastroenterology devoted to microbiota analysis, especially because it may also precede a depressive decompensation and may therefore alert for increased surveillance. Further investigation and follow-up of nondepressive patients with the $\mathrm{m}$-xylene peak is ongoing.

\section{Conflicts of Interest}

No conflict of interest to disclose.

\section{References}

1. Gorard DA, Gomborone JE, Libby GW, Farthing MJ (1996) Intestinal transit in anxiety and depression. Gut 39: 551-555.

2. Ledochowski M, Sperner-Unterweger B, Fuchs D (1998) Lactose malabsorption is associated with early signs of mental depression in females: a preliminary report. Dig Dis Sci 43: 2513-2517.

3. Panarese A, Pesce F, Porcelli P, Riezzo G, lacovazzi PA, et al. (2019) Chronic functional constipation is strongly linked to Vitamin D deficiency. World J Gastroenterol 25: 1729-1740.

4. Rao WW, Zong QQ, Zhang JW, An FR, Jackson T, et al. (2020) Obesity increases the risk of depression in children and adolescents: Results from a systematic review and meta-analysis. J Affect Disord 267: 78-85.

5. Haynes A, Kersbergen I, Sutin A, Daly M, Robinson E (2019) Does perceived overweight increase risk of depressive symptoms and suicidality beyond objective weight status? A systematic review and meta-analysis. Clin Psychol Rev 73: 101753.

6. Ambrósio G, Kaufmann FN, Manosso L, Platt N, Ghisleni G, et al. (2018) Depression and peripheral inflammatory profile of patients with obesity. Psychoneuroendocrinology 91: 132-141.

7. Jung SJ, Woo HT, Cho S, Park K, Jeong S, et al. (2017) Association between body size, weight change and depression: systematic review and meta-analysis. Br J Psychiatry 211: 14-21. 
8. Cherian D, Paladugu S, Pathikonda M, Parkman HP (2012) Fatigue: a prevalent symptom in gastroparesis. Dig Dis Sci 57: 2088-2095.

9. Clauwaert N, Jones MP, Holvoet L, Vandenberghe J, Vos R, et al. (2012) Associations between gastric sensorimotor function, depression, somatization, and symptom-based subgroups in functional gastroduodenal disorders: are all symptoms equal? Neurogastroenterol Motil 24: 1088-e565.

10. Hasler WL, Parkman HP, Wilson LA, Pasricha PJ, Koch KL, et al. (2010) Psychological dysfunction is associated with symptom severity but not disease etiology or degree of gastric retention in patients with gastroparesis. Am J Gastroenterol 105: 2357-2367.

11. Haj Kheder S, Heller J, Bär JK, Wutzler A, Menge BA, et al. (2018) Autonomic dysfunction of gastric motility in major depression. $J$ Affect Disord 226: 196-202.

12. Neuendorf R, Harding A, Stello N, Hanes D, Wahbeh H (2016) Depression and anxiety in patients with Inflammatory Bowel Disease: A systematic review. J Psychosom Res 87: 70-80.

13. Addolorato G, Mirijello A, D'Angelo C, Leggio L, Ferrulli A, et al. (2008) State and trait anxiety and depression in patients affected by gastrointestinal diseases: psychometric evaluation of 1641 patients referred to an internal medicine outpatient setting. Int J Clin Pract 62: 1063-1069.

14. Tosic-Golubovic S, Miljkovic S, Nagorni A, Lazarevic D, Nikolic G (2010) Irritable bowel syndrome, anxiety, depression and personality characteristics. Psychiatr Danub 22: 418-424.

15. Liu F, Wen YF, Zhou Y, Lei G, Guo QY, et al. (2018) A meta-analysis of emotional disorders as possible risk factors for chronic periodontitis. Medicine (Baltimore) 97: e11434.

16. Molnár J, Paksy KA, Náray M (1986) Changes in the rat's motor behaviour during 4-hr inhalation exposure to prenarcotic concentrations of benzene and its derivatives. Acta Physiol Hung 67: 349-354.

17. Korsak Z, Sokal JA, Górny R (1992) Toxic effects of combined exposure to toluene and $\mathrm{m}$-xylene in animals. III. Subchronic inhalation study. Pol J Occup Med Environ Health 5: 27-33.

18. Korsak Z, Sokal JA, Swiercz R (1991) The toxic effects of combined exposure to toluene and $\mathrm{m}$-xylene in animals. II. Blood toluene and $\mathrm{m}$-xylene during single and combined exposure in rats. Pol J Occup Med Environ Health 4: 377-381.

19. MacDonald AJ, Rostami-Hodjegan A, Tucker GT, Linkens DA (2002) Analysis of solvent central nervous system toxicity and ethano interactions using a human population physiologically based kinetic and dynamic model. Regul Toxicol Pharmacol 35: 165-176.

20. Donatini B, Brunissen F, Pereira J, Grandchamp M, Flourat A, et al. (2018) Higher levels of exhaled dimethylcyclopropane in patients with small intestinal bowel overgrowth, periodontitis when associated with a medical history of cancer. J Clin Case Stu 3.

21. Camilleri M, Chedid V, Ford AC, Haruma K, Horowitz M, et al. (2018) Gastroparesis. Nat Rev Dis Primers 4: 41.

22. Brun P, Qesari M, Marconi PC, Kotsafti A, Porzionato A, et al. (2018) Herpes simplex virus type 1 infects enteric neurons and triggers gut dysfunction via macrophage recruitment. Front Cell Infect Microbiol 8: 74 .

23. Brun P, Giron MC, Zoppellaro C, Bin A, Porzionato A, et al. (2010) Herpes simplex virus type 1 infection of the rat enteric nervous system evokes small-bowel neuromuscular abnormalities. Gastroenterology 138: 1790-1801.
24. Brun P, Scarpa M, Marchiori C, Sarasin G, Caputi V, et al. (2017) Saccharomyces boulardii CNCM I-745 supplementation reduces gastrointestinal dysfunction in an animal model of IBS. PLoS One12: e0181863.

25. Vincent-Bugnas $S$, Vitale $S$, Mouline $C C$, Khaali $W$, Charbit $Y$, et al. (2013) EBV infection is common in gingival epithelial cells of the periodontium and worsens during chronic periodontitis. PLoS One 8: e80336.

26. Aggarwal T, Lamba AK, Faraz F, Tandon S (2017) Viruses: Bystanders of periodontal disease. Microb Pathog 102: 54-58.

27. Shah R, Mehta DS (2016) Prevalence of herpesviruses in gingivitis and chronic periodontitis: relationship to clinical parameters and effect of treatment. J Indian Soc Periodontol 20: 279-285.

28. Slots J, Saygun I, Sabeti M, Kubar A (2006) Epstein-Barr virus in oral diseases. J Periodontal Res 41: 235-244.

29. Kazi MMAG, Bharadwaj R (2017) Role of herpesviruses in chronic periodontitis and their association with clinical parameters and in increasing severity of the disease. Eur J Dent 11: 299-304.

30. Zhu C, Li F, Wong MC, Feng XP, Lu HX, et al. (2015) Association between herpesviruses and chronic periodontitis: $\mathrm{A}$ meta-analysis based on case-control studies. PLoS One 12: e0144319.

31. Houenou J, d'Albis MA, Daban C, Hamdani N, Delavest M, et al. (2014) Cytomegalovirus seropositivity and serointensity are associated with hippocampal volume and verbal memory in schizophrenia and bipolar disorder. Prog Neuropsychopharmacol Biol Psychiatry 48: 142-148.

32. Jaremka $L M$, Fagundes $C P$, Glaser $R$, Bennett JM, Malarkey WB, et al. (2013) Loneliness predicts pain, depression, and fatigue: understanding the role of immune dysregulation. Psychoneuroendocrinology 38: 1310-1317.

33. Schooling CM, Jones HE, Leung GM (2011) Lifecourse infectious origins of sexual inequalities in central adiposity. Int J Epidemiol 40 : 1556-1564.

34. Nabipour I, Vahdat K, Jafari SM, Pazoki R, Sanjdideh Z (2006) The association of metabolic syndrome and Chlamydia pneumoniae, Helicobacter pylori, cytomegalovirus, and Herpes simplex virus type 1: the Persian Gulf Healthy Heart Study. Cardiovasc Diabetol 5: 25.

35. Hendler SA, Barber GE, Okafor PN, Chang MS, Limsui D, et al. (2020) Cytomegalovirus infection is associated with worse outcomes in inflammatory bowel disease hospitalizations nationwide. Int J Colorectal Dis 35: 897-903.

36. Furukawa TA (2010) Assessment of mood: guides for clinicians. J Psychosom Res 68: 581-589.

37. Hamilton M (1960) A rating scale for depression. J Neurol Neurosurg Psychiatry 23: 56-62.

38. HAS (2017) Épisode dépressif caractérisé de l’adulte: prise en charge en premier recours. Haute Autorité de Santé.

39. Donatini B (2019) Intérêt de l'échographie abdominale pour l'analyse des vidanges, des reflux et de la tonicité gastro-duodénojéjuno-iléale. Hegel 9: 196-202.

40. Donatini B (2020) Dysbiose des Darms. In: Liem T, Dobler TK, Puylaert M (eds) Leitfaden Viszerale Osteopathie. $3^{\text {rd }}$ Edition, Elsevier, München 79-95. 
41. Global Burden of Disease Cancer Collaboration, Fitzmaurice C, Allen C, Barber RM, Barregard L, et al. (2017) Global, regional, and national cancer incidence, mortality, years of life lost, years lived with disability, and disability-adjusted life-years for 32 cancer groups, 1990 to 2015: A systematic analysis for the global burden of disease study. JAMA Oncol 3: 524-548.

42. Tiele A, Wicaksono A, Kansara J, Arasaradnam RP, Covington JA (2019) Breath analysis using enose and ion mobility technology to diagnose inflammatory bowel disease-a pilot study. Biosensors (Basel) 9: E55.

43. Arasaradnam RP, McFarlane M, Daulton E, Skinner J, O'Connell N, et al. (2016) Non-invasive exhaled volatile organic biomarker analysis to detect inflammatory bowel disease (IBD). Dig Liver Dis 48: 148153

44. Hicks LC, Huang J, Kumar S, Powles ST, Orchard TR, et al (2015) Analysis of Exhaled Breath Volatile Organic Compounds in Inflammatory Bowel Disease: A Pilot Study. J Crohns Colitis 9: 731737.

45. Donatini B (2018) Two sides of the same coin. Both mutations and microbiota should be considered in diseases involving the ileum. In response to Hui KY, Fernandez-Hernandez $\mathrm{H}$, Hu J, Schaffner $\mathrm{A}$, Pankratz $\mathrm{N}$, et al. Functional variants in the LRRK2 gene confer shared effects on risk for Crohn's disease and Parkinson's disease. Sci Transl Med 10: eaai7795.

46. Dryahina $K$, Smith $D$, Bortlík M, Machková $N$, Lukáš M, et al. (2017) Pentane and other volatile organic compounds, including carboxylic acids, in the exhaled breath of patients with Crohn's disease and ulcerative colitis. J Breath Res 12: 016002.

47. Donatini B, Isabelle LB (2018) Severe acne in female patients treated with isotretinoin is associated with dysbiosis and its consequences. $J$ Clin Cosmet Dermatol 2.

48. Smolinska A, Tedjo DI, Blanchet L, Bodelier A, Pierik MJ, et al (2018) Volatile metabolites in breath strongly correlate with gut microbiome in CD patients. Anal Chim Acta 1025: 1-11.

49. Qin J, Li R, Raes J, Arumugam M, Burgdorf KS, et al (2010) A human gut microbial gene catalogue established by metagenomic sequencing. Nature 464: 59-65.

50. Beeken WL, Kanich RE (1973) Microbial flora of the upper small bowel in Crohn's disease. Gastroenterology 65: 390-397.

51. Patel N, Alkhouri N, Eng K, Cikach F, Mahajan L, et al. (2014) Metabolomic analysis of breath volatile organic compounds reveals unique breath prints in children with inflammatory bowel disease: $\mathrm{A}$ pilot study. Aliment Pharmacol Ther 40: 498-507.

52. Rana SV, Sharma S, Malik A, Kaur J, Prasad KK, et al. (2013) Small intestinal bacterial overgrowth and orocecal transit time in patients of inflammatory bowel disease. Dig Dis Sci 58: 2594-2598.

53. Donatini B, Le Blaye I (2015) Mycobacterium avium paratuberculosis (MAP) and Cytomegalovirus (CMV) are frequently detected in the saliva of patients recently diagnosed with Crohn Disease (CD) whereas oral Propionibacterium acnes (PA) or methylacetate (MA) in their breath is rare. J Biosciences Med 3: 13-18.

54. Greco A, Caviglia GP, Brignolo P, Ribaldone DG, Reggianiet $S$, et al. (2015) Glucose breath test and Crohn's disease: Diagnosis of small intestinal bacterial overgrowth and evaluation of therapeutic response. Scand J Gastroenterol 50: 1376-1381.

55. de Lacy Costello BP, Ledochowski M, Ratcliffe NM (2013) The importance of methane breath testing: a review. J Breath Res 7: 024001.
56. Ledochowski M, Widner B, Murr C, Sperner-Unterweger B, Fuchs D (2001) Fructose malabsorption is associated with decreased plasma tryptophan. Scand J Gastroenterol 36: 367-371.

57. Ledochowski M, Widner B, Bair H, Probst T, Fuchs D (2000) Fructoseand sorbitol-reduced diet improves mood and gastrointestinal disturbances in fructose malabsorbers. Scand J Gastroenterol 35: 1048-1052.

58. Lin P, Ding B, Feng C, Yin S, Zhang T, et al. (2017) Prevotella and Klebsiella proportions in fecal microbial communities are potential characteristic parameters for patients with major depressive disorder. J Affect Disord 207: 300-304.

59. Jiang $H$, Ling $Z$, Zhang $Y$, Mao $H, M a ~ Z$, et al. (2015) Altered fecal microbiota composition in patients with major depressive disorder. Brain Behav Immun 48: 186-194.

60. Zheng P, Zeng B, Zhou C, Liu M, Fang Z, et al. (2016) Gut microbiome remodeling induces depressive-like behaviors through a pathway mediated by the host's metabolism. Mol Psychiatry 21: 786-796.

61. Florin TH, Woods HJ (1995) Inhibition of methanogenesis by human bile. Gut 37: 418-421.

62. Kayser BD, Prifti E, Lhomme M, Belda E, Dao MC, et al. (2019) Elevated serum ceramides are linked with obesity-associated gut dysbiosis and impaired glucose metabolism. Metabolomics 15: 140.

63. Kaur J, Rana SV, Gupta R, Gupta V, Sharma SK, et al. (2014) Prolonged orocecal transit time enhances serum bile acids through bacterial overgrowth, contributing factor to gallstone disease. J Clin Gastroenterol 48: 365-369.

64. Pimentel $\mathrm{M}$, Kong $\mathrm{Y}$, Park $\mathrm{S}$ (2004) IBS subjects with methane on lactulose breath test have lower postprandial serotonin levels than subjects with hydrogen. Dig Dis Sci 49: 84-87.

65. El-Salhy M, Gilja OH, Gundersen D, Hausken T (2014) Endocrine cells in the oxyntic mucosa of the stomach in patients with irritable bowel syndrome. World J Gastrointest Endosc 6: 176-185.

66. El-Salhy M, Vaali K, Dizdar V, Hausken T (2010) Abnormal smallintestinal endocrine cells in patients with irritable bowel syndrome. Dig Dis Sci 55: 3508-3513.

67. El-Salhy M, Gundersen D, Hatlebakk JG, Gilja OH, Hausken T (2014) Abnormal rectal endocrine cells in patients with irritable bowel syndrome. Regul Pept 188: 60-65.

68. Yasi EA, Allen AA, Sugianto W, Peralta-Yahya P (2019) Identification of three antimicrobials activating serotonin receptor 4 in colon cells. ACS Synth Biol 8: 2710-2717.

69. İliaz R, Akyüz F, Yeğen G, Örmeci A, Göktürk S, et al. (2018) Does the number of mucosal immune cells differ in irritable bowel syndrome and its subtypes? Turk J Gastroenterol 29: 384-391.

70. Cremon C, Gargano L, Morselli-Labate AM, Santini D, Cogliandro RF, et al. (2009) Mucosal immune activation in irritable bowel syndrome: gender-dependence and association with digestive symptoms. Am J Gastroenterol 104: 392-400.

71. Boaz M, Kislov J, Dickman R, Wainstein J (2011) Obesity and symptoms suggestive of gastroparesis in patients with type 2 diabetes and neuropathy. J Diabetes Complications 25: 325-328.

72. Van Citters GW, Lin HC (1999) The ileal brake: a fifteen-year progress report. Curr Gastroenterol Rep 1: 404-409.

73. Maljaarsa PWJ, Peters HPF, Melab DJ, Masclee AM (2008) Ileal brake: A sensible food target for appetite control. A review. Physiol Behav 95: 271-281. 
74. Van Citters GW, Lin HC (2006) Ileal brake: neuropeptidergic control of intestinal transit. Curr Gastroenterol Rep 8: 367-373.

75. Shin HS, Ingram JR, McGill AT, Poppitt SD (2013) Lipids, CHOs, proteins: can all macronutrients put a 'brake' on eating? Physiol Behav 120: 114-123.

76. Fujita K, Tokuda H, Yamamoto N, Kainuma S, Kawabata T, et al. (2017) Incretins amplify TNF- $\alpha$-stimulated IL- 6 synthesis in osteoblasts: Suppression of the IKB/NF-KB pathway. Int J Mol Med 4: 1053-1060.

77. Bouwman JJ, Visseren FL, Bouter KP, Diepersloot RJ (2008) Infectioninduced inflammatory response of adipocytes in vitro. Int J Obes (Lond) 6: 892-901. 